\title{
DENDROFLORA DA ESCOLA ESTADUAL PROFESSORA CLARA MENEZES DIAS, JAÍBA-MG: ESTRUTURA, SÍNDROMES DE DISPERSÃO PRIMÁRIA E POLINIZAÇÃO
}

\author{
DENDROFLORA OF PROFESSORA CLARA MENEZES DIAS STATE SCHOOL, \\ JAIIBA-MG: STRUCTURE, SYNDROMES OF PRIMARY DISPERSION AND \\ POLLINATION
}

\begin{abstract}
Márcio Venícius Barbosa Xavier ${ }^{1}$, Elaine Soares de Almeida², Ana Paula Mota Fonseca², Lucas Verciane Oliveira Almeida ${ }^{2}$
\end{abstract}

\begin{abstract}
RESUMO
Objetivou-se conhecer a dendroflora da Escola Estadual Professora Clara Menezes Dias, Jaíba-MG, caracterizar sua estrutura, distribuição das síndromes de dispersão primária e polinização, e gerar uma chave de identificação das espécies. Foram avaliados todos os indivíduos vivos com circunferência à altura do peito $(C A P) \geq a 15 \mathrm{~cm}$, sendo categorizados em nativo da região, nativo do Brasil, exótico cultivado e exótico naturalizado. A investigação das síndromes de dispersão primária e polinização foi baseada na análise de frutos e flores, respectivamente. A estrutura da comunidade foi calculada por meio da Frequência, Densidade Relativa e Dominância Relativa. A diversidade foi analisada pelos índices de Shannon (H') e de Equabilidade (J'). Foram encontrados 84 indivíduos, distribuídos em 11 famílias, 23 gêneros e 25 espécies. Fabaceae foi a família mais representativa, com 10 espécies. $57 \%$ das espécies são nativas e $43 \%$ são exóticas. As síndromes de dispersão primária e polinização predominantes foram anemocoria e melitofilia, respectivamente. O índice de Shannon foi 2,11, considerado intermediário para o total de indivíduos amostrados e o de Equabilidade foi 0,657, demonstrando uma baixa uniformidade nas proporções do número de indivíduos em relação ao número de espécies na área.
\end{abstract}

Palavras-chave: Arborização; Árvores; Floresta urbana; Ecologia urbana; chave de identificação.

\section{ABSTRACT}

The objective was to get to know the dendroflora of Professora Clara Menezes Dias State School, Jaíba$M G$, to characterize its structure, distribution of syndromes of primary dispersion and pollination, and to generate a species identification key. All living individuals with a circumference at breast height (CAP) $\geq 15$ $\mathrm{cm}$ were evaluated, being categorized as native to the region, native to Brazil, cultivated exotic, and naturalized exotic. The investigation of primary dispersion and pollination syndromes was were based on the analysis of fruits and flowers, respectively. The community structure was calculated using Frequency, Relative Density and Relative Dominance. Diversity was analyzed using the Shannon ( $\left.H^{\prime}\right)$ and Equability $(\mathrm{J} ')$ indexes. A total of 84 individuals were found, distributed in 11 families, 23 genera and 25 species. Fabaceae was the most representative family, with 10 species. $57 \%$ of the species are native and $43 \%$ are exotic. The primary dispersion and pollination syndromes were anemochory and melittophily, respectively. The Shannon index was 2.11, considered intermediate for the total of sampled individuals and the Equability index was 0.657 , showing a low uniformity in the proportions of the number of individuals in relation to the number of species in the area.

Keywords: Afforestation; Trees; Urban forest; Urban ecology; identification key.

Recebido em 05.08.2020 e aceito em 16.03.2021

1 Engenheiro Florestal. Mestrando no Programa de Pós-Graduação em Biologia Vegetal da UFMG (Instituto de Ciências Biológicas). Belo Horizonte/MG. Email: mvbx23@gmail.com

2 Graduandos em Engenharia Florestal. Instituto de Ciências Agrárias da UFMG. Montes Claros/MG. Emails: elainesoaresalmeida2015@gmail.com / anapaulamota577@gmail.com / lucasverciane1@hotmail.com 


\section{INTRODUÇÃO}

Atualmente, o Brasil possui cerca de $84,4 \%$ de sua população vivendo em cidades (IBGE, 2020). O desenvolvimento urbano ocorreu de forma rápida e desordenada, ocasionando diversos problemas econômicos e sociais, mas, sobretudo, distúrbios ecológicos (DOS SANTOS MAMEDE et al., 2014).

A urbanização, a princípio, não incluiu a permanência de áreas verdes naturais e projetos paisagísticos nas cidades. Estes espaços foram destinados a outros fins, como por exemplo, habitação e parques industriais (ALMAS; CONWAY, 2016). Fato que gerou, nos últimos 50 anos, necessidade iminente de introduzir esse recurso a fim de criar vínculos com a natureza (ALMAS; CONWAY, 2016). A inserção dos espaços verdes urbanos promove o bem-estar humano e animal, devido atuação significativa na purificação do ar, melhoria do clima pela retenção da umidade, diminuição da amplitude térmica e decréscimo das poluições sonora e visual (CABRAL, 2013). Ainda, oportuniza habitat para a fauna (CABRAL, 2013) e, consequentemente, fornece serviços ecossistêmicos indispensáveis, relacionados a polinização e dispersão de frutos e sementes.

O sucesso da interação do meio artificial com o natural depende da escolha e manejo adequado da espécie. Esses fatores possibilitam um melhor desempenho e cumprimento das funções ecológica, estética e social da arborização dentro dos espaços (FIRMO et al., 2019). Em regiões áridas e semiáridas, especialmente, as árvores atuam na estabilização e melhoria microclimática, reduzindo a radiação solar direta e aumentando o conforto térmico (DE SOUZA; NOGUEIRA; DA COSTA SARAIVA, 2018). Além disso, espaços arborizados incentivam a educação ambiental, pois o contato direto com esse elemento desperta interesse pela preservação da natureza. Em locais de ensino, por exemplo, os vegetais ajudam a promover o conhecimento e compreensão sobre a sua importância e funcionalidade no meio ambiente, o que auxilia no combate à cegueira botânica, isto é, a dificuldade de perceber a presença das plantas (SOUSA et al., 2019).

Nesse contexto, estimular o pensamento sobre a importância das plantas nos ambientes urbanos, sobretudo em locais educacionais, pode incitar uma postura crítica e responsável frente aos problemas socioambientais existentes (SOUSA et al., 2019). Assim, objetivou-se conhecer a flora arbórea da Escola Estadual Professora Clara Menezes Dias em Jaíba-MG, caracterizar sua estrutura, distribuição das síndromes de dispersão primária e polinização, e gerar uma chave de identificação das espécies. 


\section{MATERIAL E MÉTODOS}

\section{Área de estudo}

A Escola Estadual Professora Clara Menezes Dias (EEPCMD) está localizada em Jaíba, cidade brasileira da mesorregião norte de Minas Gerais (14057'50" 15032'13"S, 43012'32" $44^{0} 04^{\prime} 37^{\prime \prime W}$ ) (Figura 1). O município ocupa uma extensão equivalente a $2.740 \mathrm{~km}^{2}$ e possui 38.413 habitantes (IBGE, 2020).
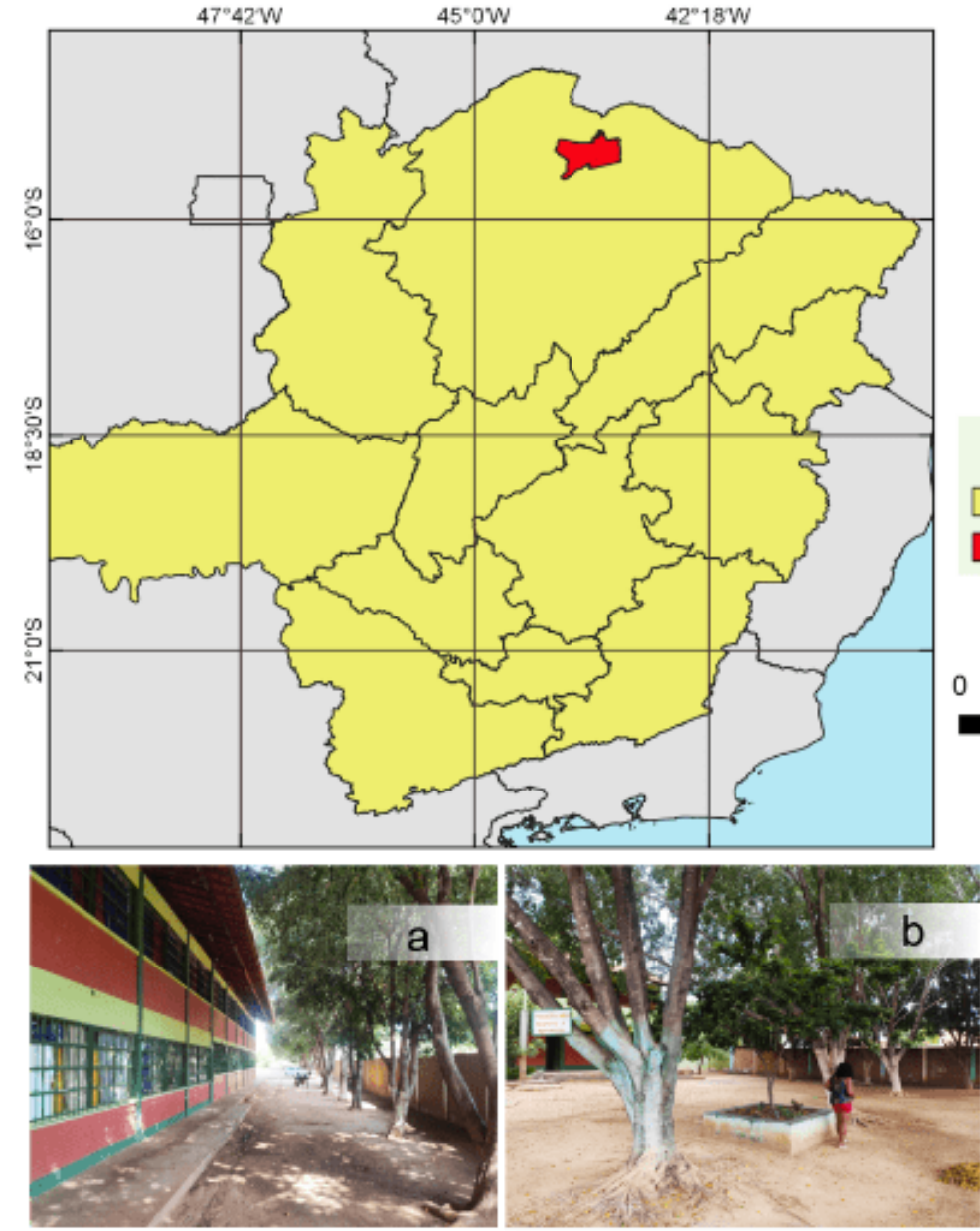

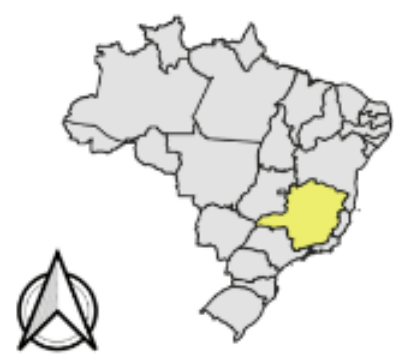

Elementos do mapa

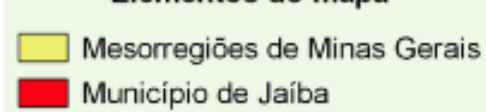

Município de Jaíba

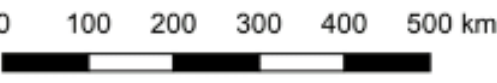

Sistema de coordenadas geográficas: Datum SIRGAS 2000.

Bases cartográficas: IBGE, 2017.

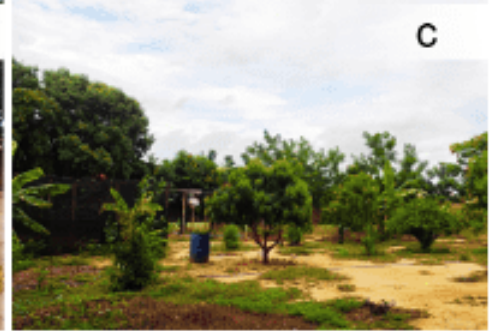

Fonte: Dos autores (2020)

Figura 1. Localização geográfica da Escola Estadual Prof. ${ }^{a}$ Clara Menezes Dias, Jaíba, MG. a - b - c: áreas arborizadas.

Figure 1. Geographical location of Prof. ${ }^{a}$ Clara Menezes Dias State School, Jaíba, MG.a-b-c: wooded areas.

O clima da região é classificado como tropical quente do subtipo semiárido, com período de seca superior a seis meses. A precipitação média anual gira em torno de $800 \mathrm{~mm}$, distribuída irregularmente, sendo que de novembro a março ocorrem as maiores precipitações e de abril a setembro as menores. A temperatura média anual é de $26,6{ }^{\circ} \mathrm{C}$, onde o mês de junho é o mais frio $\left(24,5^{\circ} \mathrm{C}\right)$ e outubro o mais quente $\left(28,9^{\circ} \mathrm{C}\right)$ (INMET, 2020). A cobertura vegetal natural é composta pela floresta estacional decidual. 


\section{Procedimentos metodológicos}

O levantamento foi executado em janeiro de 2020 e considerou as espécies inseridas na arborização. O critério de inclusão para a avaliação dos indivíduos vivos foi a circunferência à altura do peito $(\mathrm{CAP}) \geq \mathrm{a} 15 \mathrm{~cm}$. A altura total de cada indivíduo foi determinada usando o método da vara.

A maior parte das espécies foram identificadas no local, para as demais foi consultado o banco de dados virtual do herbário Norte Mineiro (MCCA). A origem fitogeográfica seguiu a Flora do Brasil (2020), sendo categorizadas em nativa da região, nativa do Brasil, exótica cultivada (só sobrevive com a intervenção humana) e exótica naturalizada (sobrevive sem a intervenção humana). Espécies identificadas ao nível de gênero não foram classificadas. Para a confecção da chave de identificação, utilizou-se as descrições morfológicas propostas por Gonçalves e Lorenzi (2007).

A investigação das síndromes de dispersão primária e polinização foram baseadas na análise de frutos e flores, respectivamente. A coloração, cheiro e recursos disponíveis, foram anotados em campo. Para a caracterização das síndromes de dispersão primária, foram analisados a cor, morfologia, tamanho e estruturas acessórias, seguindo Van Der Pijl (1982); sendo classificadas em anemocoria (dispersão pelo vento), autocoria (dispersão pela própria planta), barocoria (dispersão por gravidade), hidrocoria (dispersão pela água), mamaliocoria (dispersão por mamíferos), ornitocoria (dispersão por pássaros), quiropterocoria (dispersão por morcegos). Para caracterizar as síndromes de polinização, analisou-se a cor, odor e recursos florais (néctar, pólen, óleo e resina) (FAEGRI; VAN DER PIJL, 1979). Assim, foram divididas em melitofilia (polinização por abelhas e vespas), psicofilia (polinização por borboletas) e anemofilia (polinização pelo vento). Para as espécies que não floresceram e frutificaram durante o período do estudo, foram consultados literatura especializada e material de herbários virtuais.

A estrutura da comunidade foi calculada a partir dos parâmetros fitossociológicos Frequência Absoluta (número de indivíduos por espécie), Densidade Relativa (proporção de indivíduos de cada espécie na arborização) e Dominância Relativa (porcentagem da área basal de determinada espécie em relação a área basal de todas as espécies amostradas). A diversidade foi analisada com o índice de Shannon $\left(\mathrm{H}^{\prime}\right)$ e de Equabilidade (J').

\section{RESULTADOS E DISCUSSÃO}

\section{Identificação, origem e frequência}

Foram inventariados 84 indivíduos, distribuídos em 11 famílias, 23 gêneros e 25 espécies (Tabela 1; Figura 2). 
Tabela 1. Frequência, densidade, dominância e síndromes de polinização e dispersão das espécies que compõem a arborização da Escola Estadual Prof. ${ }^{a}$ Clara Menezes Dias, Jaíba, MG.

Table 1. Frequency, density, dominance, pollination syndromes and dispersion syndromes of the species that make up the afforestation of the Prof. ${ }^{a}$ Clara Menezes Dias State School, Jaíba, MG.

\begin{tabular}{|c|c|c|c|c|c|c|c|}
\hline Família / Nome científico & Nome popular & FA & DeR & DoR & Or & SP & SD \\
\hline \multicolumn{8}{|l|}{ Anacardiaceae } \\
\hline Anacardium occidentale L. & Cajú & 2 & 2,38 & 0,08 & NB & Mel. & Mam. (Sinz.) \\
\hline Mangifera indica L. & Manga & 3 & 3,57 & 3,07 & EC & Mel. & Mam. (Sinz.) \\
\hline Spondias sp. & Umbú-cajá & 1 & 1,19 & 0,2 & - & Mel. & Mam. (End., Sinz.) \\
\hline Spondias tuberosa Arruda & Umbú & 1 & 1,19 & 0,68 & NR & Mel. & Mam. (End., Sinz.) \\
\hline \multicolumn{8}{|l|}{ Arecaceae } \\
\hline Cocos nucifera L. & Coco & 1 & 1,19 & 0,09 & EN & Mel./Ane & Hid. \\
\hline \multicolumn{8}{|l|}{ Bignoniaceae } \\
\hline $\begin{array}{l}\text { Handroanthus impetiginosus } \\
\text { (Mart. ex DC.) Mattos }\end{array}$ & Ipê-roxo & 1 & 1,19 & 0,02 & NR & Mel. & Anem. \\
\hline $\begin{array}{l}\text { Handroanthus chrysotrichus } \\
\text { (Mart. ex DC.) Mattos }\end{array}$ & Ipê-amarelo & 5 & 5,95 & 0,59 & NR & Mel. & Anem. \\
\hline \multicolumn{8}{|l|}{ Bixaceae } \\
\hline Bixa orellana L. & Corante & 1 & 1,19 & 0,05 & NB & Mel. & Orn. (End.) \\
\hline \multicolumn{8}{|l|}{ Chrysobalanaceae } \\
\hline Moquilea tomentosa Benth & Oiti & 44 & 52,4 & 75,12 & NB & Mel. & Mam. (End., Sinz.) \\
\hline \multicolumn{8}{|l|}{ Fabaceae } \\
\hline $\begin{array}{l}\text { Albizia polycephala (Benth.) } \\
\text { Killip ex Record }\end{array}$ & Albizia & 1 & 1,19 & 0,21 & NB & Mel. & Aut. \\
\hline $\begin{array}{l}\text { Bauhinia variegata var. } \\
\text { candida Voigt }\end{array}$ & Pata-de-vaca & 1 & 1,19 & 0,09 & EC & Mel. & Aut./Bar. \\
\hline Cassia fistula L. & Chuva-de-ouro & 1 & 1,19 & 0,04 & EC & Mel. & Aut. \\
\hline $\begin{array}{l}\text { Cenostigma pluviosum (DC.) } \\
\text { Gagnon \& G.P. Lewis }\end{array}$ & Sibipuruna & 1 & 1,19 & 0,75 & NR & Mel. & Aut./Bar. \\
\hline $\begin{array}{l}\text { Delonix regia (Bojer ex Hook.) } \\
\text { Raf. }\end{array}$ & Flamboyant & 1 & 1,19 & 0,05 & EC & Mel. & Aut. \\
\hline Goniorrhachis marginata Taub. & Itapicurú & 1 & 1,19 & 0,27 & NB & Mel. & Bar. \\
\hline $\begin{array}{l}\text { Leucaena leucocephala (Lam.) } \\
\text { de Wit }\end{array}$ & Leucena & 1 & 1,19 & 0,17 & EN & Mel. & Bar. \\
\hline $\begin{array}{l}\text { Paubrasilia echinata (Lam.) } \\
\text { Gagnon, H.C. Lima \& G.P. } \\
\text { Lewis }\end{array}$ & Pau-brasil & 1 & 1,19 & 0,07 & NB & Mel. & Aut./Bar. \\
\hline $\begin{array}{l}\text { Peltophorum dubium (Spreng.) } \\
\text { Taub. }\end{array}$ & Canafístula & 2 & 2,38 & 0,57 & NR & Mel. & Anem. \\
\hline Pterogyne nitens Tul. & Amendoin-bravo & 1 & 1,19 & 0,71 & NR & Mel. & Anem. \\
\hline \multicolumn{8}{|l|}{ Meliaceae } \\
\hline Azadirachta indica A. Juss. & Niim & 4 & 4,76 & 0,88 & $\mathrm{EC}$ & Mel. & Orn./Qui. (End.) \\
\hline \multicolumn{8}{|l|}{ Moraceae } \\
\hline Ficus benjamina L. & Figueira & 4 & 4,76 & 15,72 & EC & Mel. & Orn. (End.) \\
\hline Morus nigra L. & Amora & 2 & 2,38 & 0,35 & EC & Mel. & Orn. (End.) \\
\hline \multicolumn{8}{|l|}{ Moringaceae } \\
\hline Moringa oleifera Lam. & Moringa & 1 & 1,19 & 0,1 & EC & Mel. & Anem. \\
\hline \multicolumn{8}{|l|}{ Nyctaginaceae } \\
\hline Bougainvillea sp. & Três-marias & 2 & 2,38 & 0,09 & NB & Psi. & Anem. \\
\hline \multicolumn{8}{|l|}{ Verbenaceae } \\
\hline Duranta erecta L. & Pingo-de-ouro & 1 & 1,19 & 0,05 & EN & Psi. & Orn. (End.) \\
\hline
\end{tabular}

Nota: Frequência Absoluta (FA); Densidade Relativa (DeR); Dominância Relativa (DoR). Origem (Or): Exótica cultivada (EC), Exótica naturalizada (EN), Nativa do Brasil (NB), Nativa da região (NR). Síndrome de Polinização (SP): Melitofilia (Mel.), Psicofilia (Psi.), Anemofilia (Anem.). Síndrome de dispersão (SD); Autocoria (Aut.); Barocoria (Zooc.); Anemocoria (Anec.); Hidrocoria (Hid.); mamaliocoria (Mam.,), ornitocoria (Orn.), quiropterocoria (Qui.), Endozoocoria (End.), Sinzoocoria (Sinz.). 

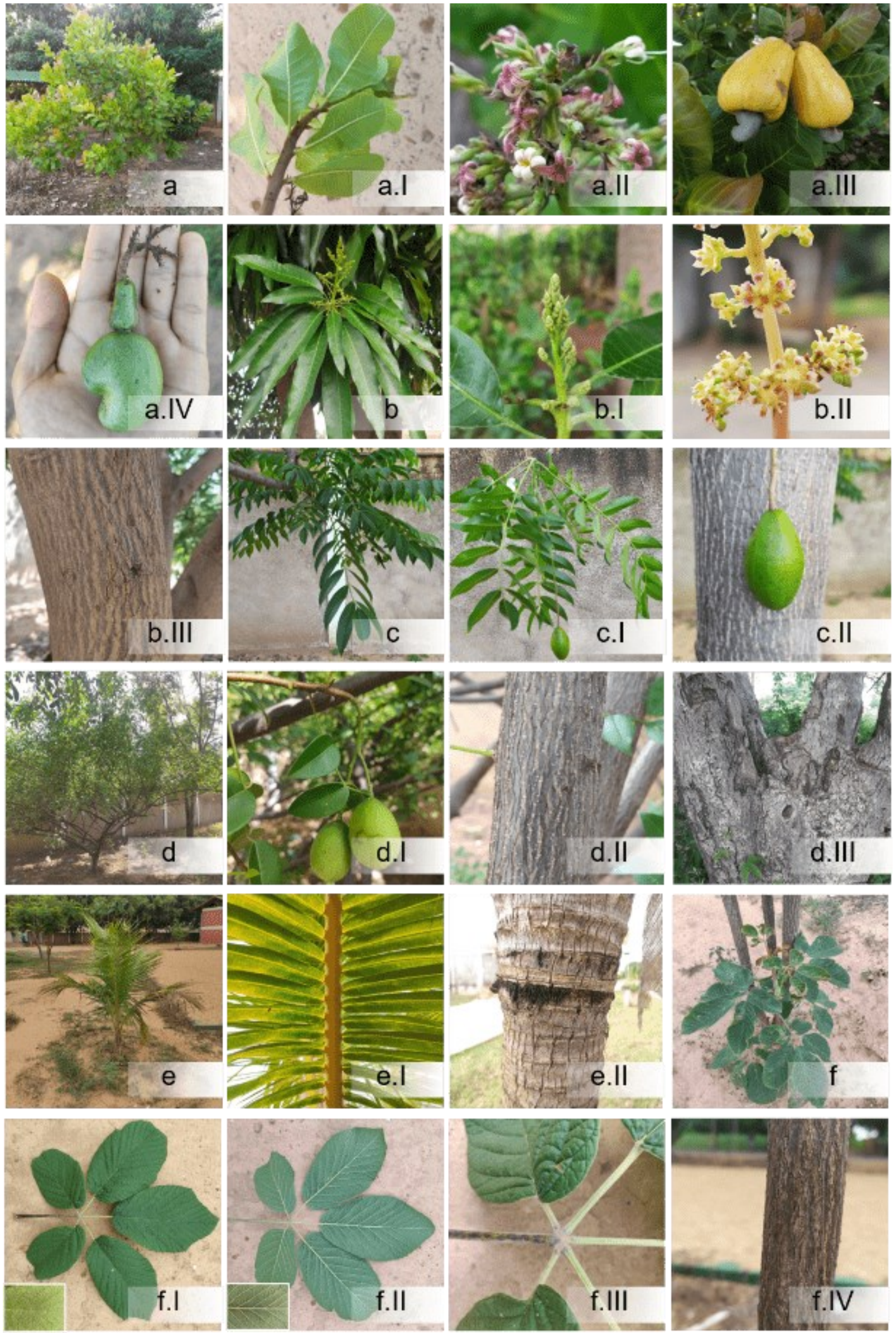

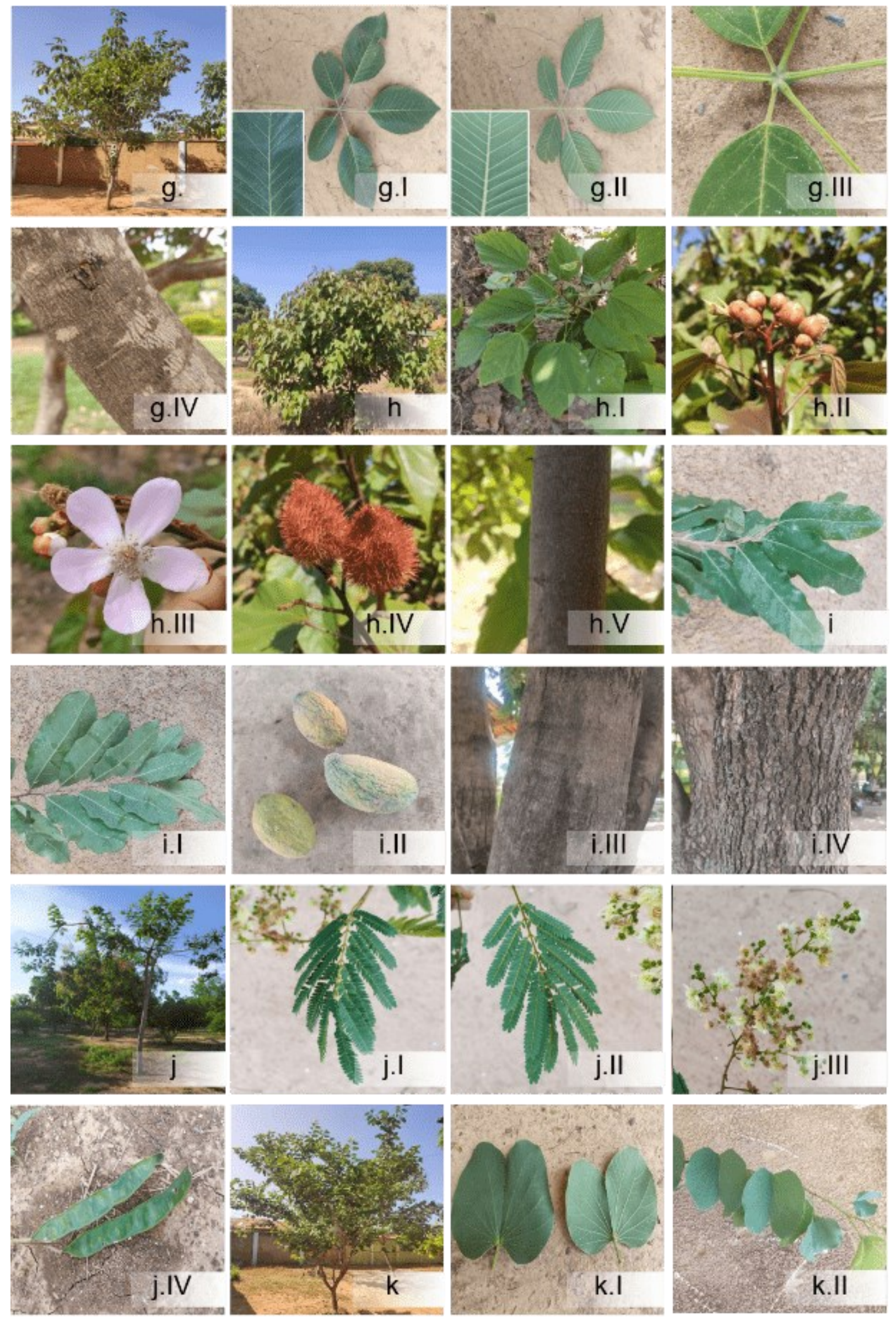

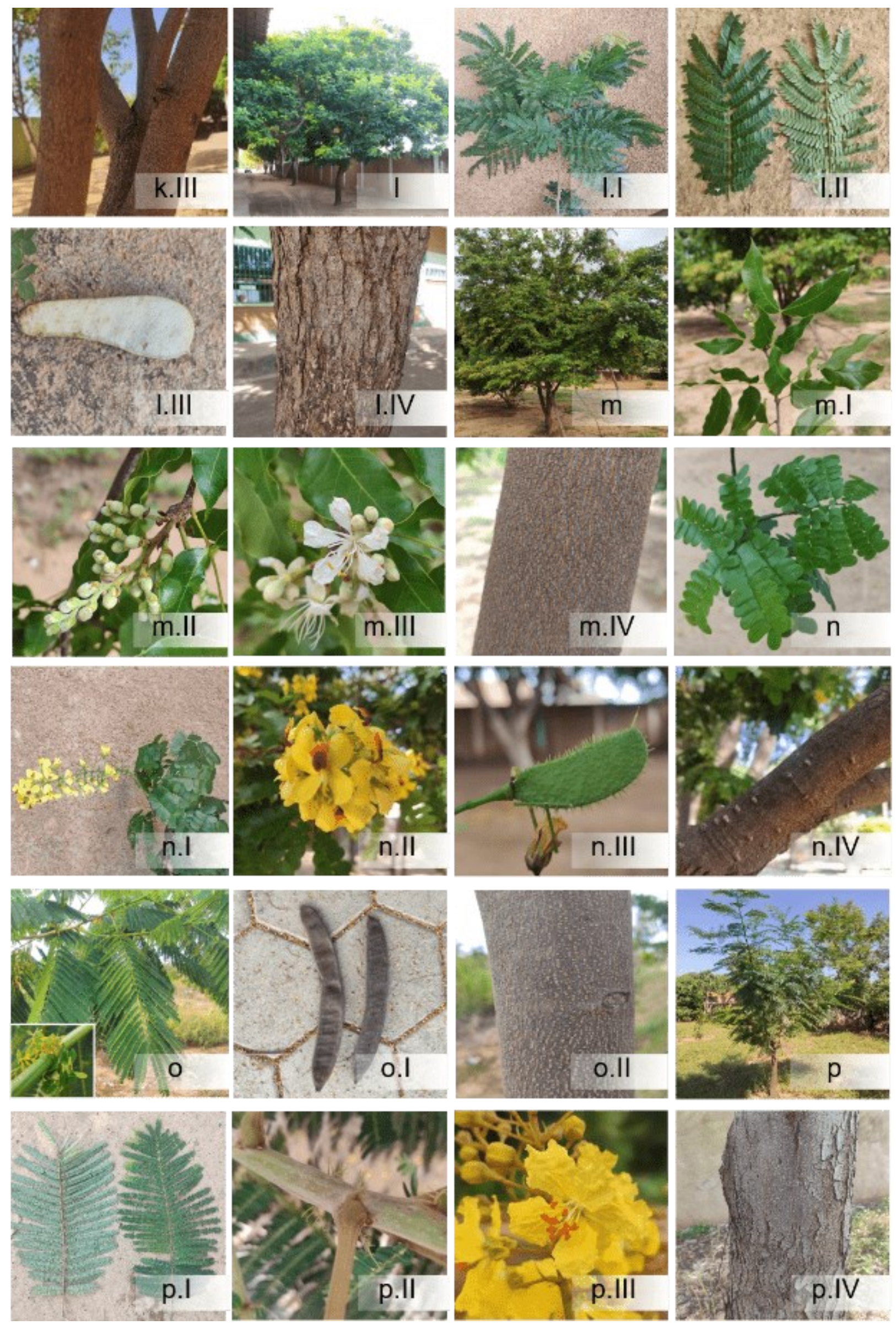

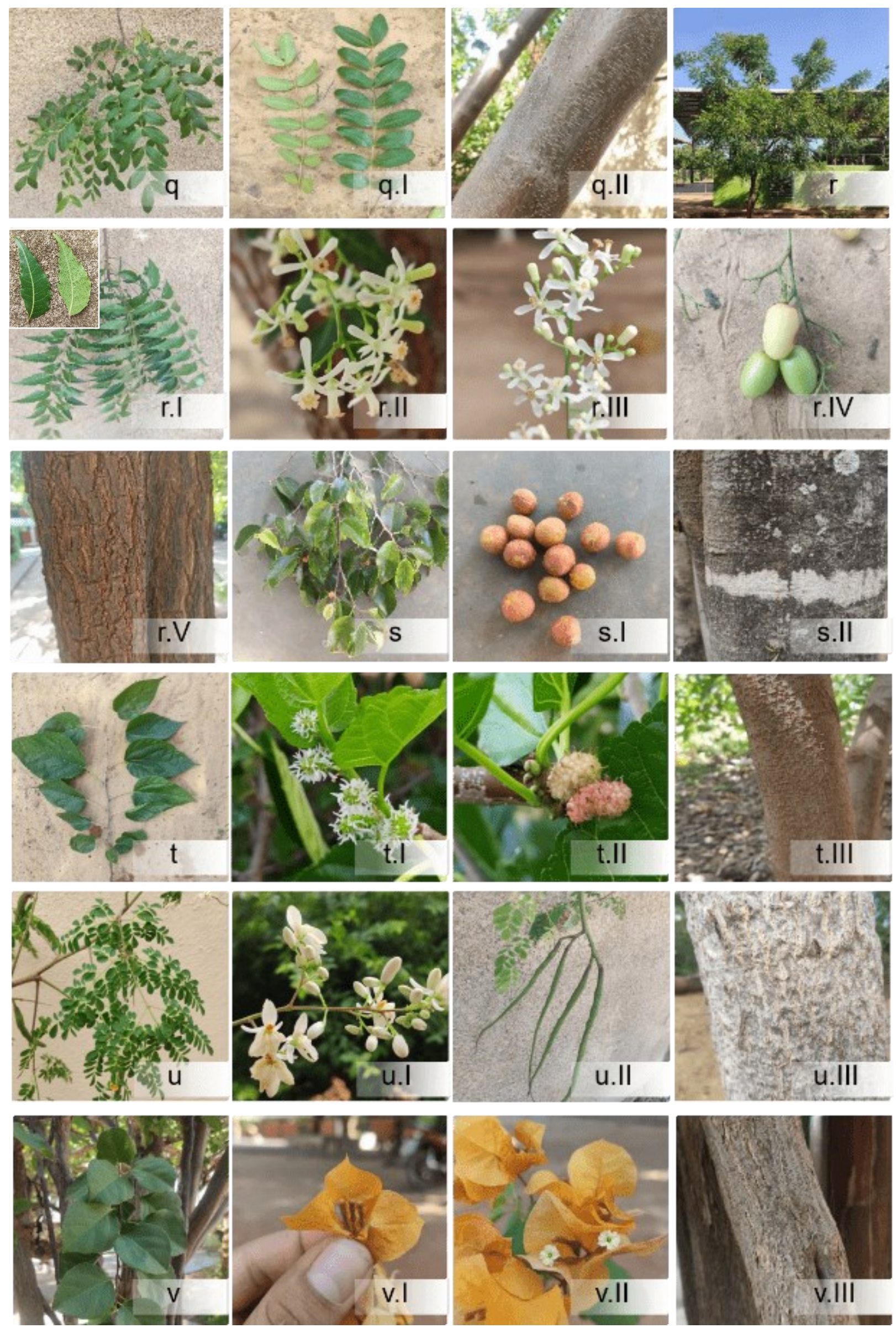

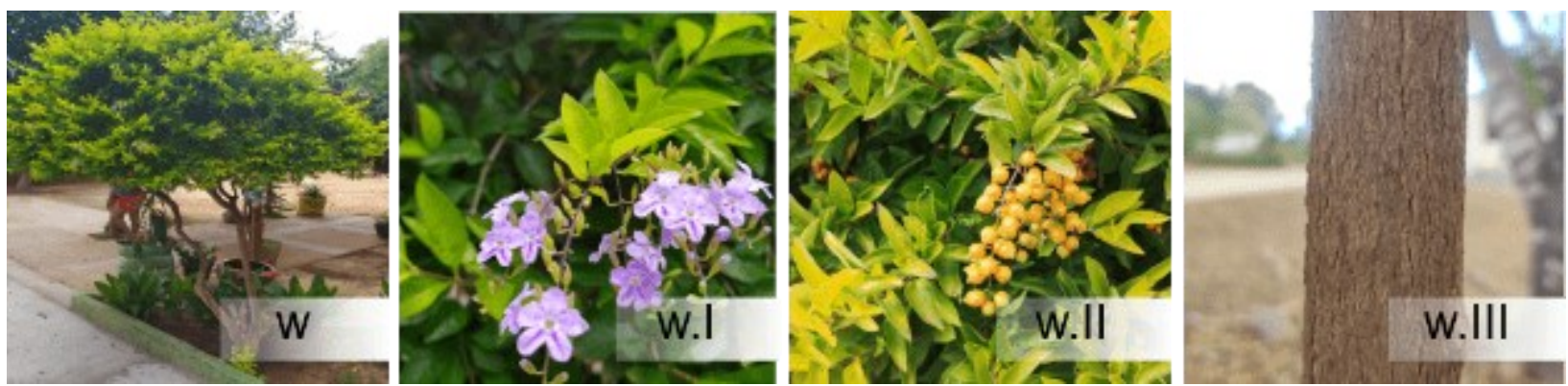

Nota: a-aVI Anacardium occidentale - a. planta; a.I. ramo com folhas; a.II. Inflorescência; a.III. fruto e pseudofruto maduros; a.IV. fruto e pseudofruto imaturos. b-b.III Mangifera indica - b. folhas; b.I. botões florais; b.II. Inflorescência; b.III. ritidoma. c-c.II Spondias sp. - c-c.l. folhas; c.II fruto. d-d.III Spondias tuberosa - d. planta; d.I. frutos. d.II. ritidoma jovem; d.III. ritidoma velho. e-e.II Cocos nucifera - e. planta; e.I folha; e.II. estipe. f-f.IV Handroanthus chrysotrichus - f. planta; f.I folha na face adaxial; f.II. folha na face abaxial; f.III. pecíolo; f.IV ritidoma. g-gIV Handroanthus impetiginosus - g. planta; g.I. folha na face adaxial; g.II. folha na face abaxial; g.III. peciólulo; g.IV. ritidoma. h-hV Bixa orellana - h. planta; h.I. ramo com folhas; h.II. botões florais; h.III. flor; h.IV. frutos; h.V. ritidoma. i-ilV- Moquilea tomentosa - i. folhas; i.I. ramo com folhas; i.ll. frutos; i.lll. ritidoma jovem; i.IV. ritidoma velho. j-j.IV Albizia polycephala - j. planta; j.I. folha na face adaxial; j.II. folha na face abaxial; j.III. inflorescência; j.IV. frutos. k-k.III Bauhinia variegata var. candida - k. planta; k.I. folhas nas faces adaxial e abaxial respectivamente; k.II. ramo com folhas; k.III ritidoma. I-I.IV Cenostigma pluviosum - I. planta; I.I. ramo com folhas; I.II. folhas nas faces adaxial e abaxial respectivamente; I.III. fruto; I.IV. ritidoma. $\mathrm{m}$-m.IV Goniorrhachis marginata - m. planta; m.I. ramo com folhas; m.II. botões florais; m.III. flores; m.IV ritidoma. n-n.IV Paubrasilia echinata - n. ramo com folhas; n.I inflorescência; n.II. flores; n.III. fruto; n.IV. ritidoma. o-o.II Delonix regia - o. ramo com folhas; o.I frutos; o.II ritidoma. p-p.IV Peltophorum dubium - p. planta; p.I. folhas nas faces abaxial e adaxial respectivamente; p.II. pecíolo e estipula foliar; p.III. flor; p.IV. ritidoma. q-q.II Pterogyne nitens - q. ramo com folhas; q.I. folhas nas faces abaxial e adaxial respectivamente; q.II. ritidoma. r-r.V Azadirachta indica - r. planta; r.l. ramo com folhas; r.Il-r.III. inflorescência; r.IV. frutos; r.V. ritidoma. s-s.II Ficus benjamina - s. ramos com folhas; s.I. frutos; s.III. ritidoma. t-t.II Morus nigra - t. ramo com folhas; t.l. inflorescência; t.II. infrutescência. t.III. ritidoma. u-u.III Moringa oleiffera - u. ramo com folhas; u.I. inflorescência; u.II. ramo com frutos; u.III. ritidoma. v-v.III Bougainvillea sp. - v. ramo com folhas; v.I.-v.II. brácteas e flores. W-w.III Duranta erecta - w. indivíduo; w.I. flores; w.II. frutos; w.III ritidoma.

Figura 2. Dendroflora da Escola Estadual Prof. ${ }^{a}$ Clara Menezes Dias, Jaíba, MG.

Figure 2. Dendroflora of the Prof. ${ }^{a}$ Clara Menezes Dias State School, Jaíba, MG.

\section{Chave dicotômica para identificação das espécies}

1. Folhas com único limbo.

2. Filotaxia oposta; hábito arbustivo; corolas lilás; frutos alaranjados.

Duranta erecta

2'. Filotaxia alterna

3. Presença de brácteas florais, chamativas

Bougainvillea sp.

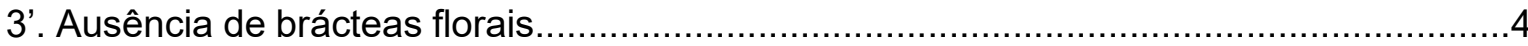

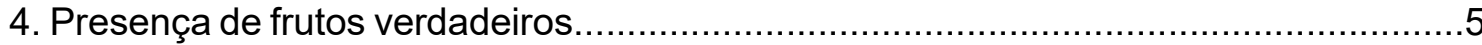

5. Frutos simples.

6

6. Frutos secos, cápsulas equinocárpicas, deiscentes

Bixa orellana

6'. Frutos carnosos

7. Presença de exsudação e cheiro característico; folhas oblongo-lanceoladas, glabras. Mangifera indica

7'. Ausência de exsudação e cheiro característico; folhas oblongo-elípticas, tomentosas. Moquilea tomentosa

5'. Frutos múltiplos ou infrutescência 
8.Frutos múltiplos, brancos quando imaturos e vináceos quando maduros; folhas cordiformes, margem dentada.

Morus nigra

8'. Infrutescência sicônio, esférico; folhas elípticas, glabras, lustrosas, margem inteira; exsudação leitosa ao se destacaram as folhas; estípula terminal evidente

Ficus benjamina

4'. Presença de pseudofrutos Anacardium occidentale

1'. Folhas com limbo dividido 9

9. Divisão em dois folíolos Bauhinia variegata var. candida

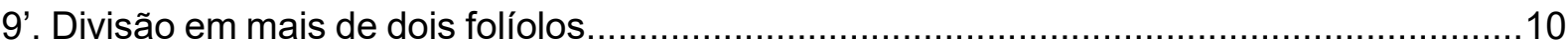

10. Folhas opostas .11

11. Ápice e base foliolar atenuados, margem inteira; nervuras primárias e secundárias evidentes na face abaxial; corolas róseas-lilás; frutos glabros Handroanthus impetiginosus

11'. Ápice foliolar agudo, base truncada, margem com dentes espaçados; nervuras primárias, secundárias, terciárias e quaternárias evidentes na face abaxial; corolas amarelas; frutos pilosos Handroanthus chrysotrichus

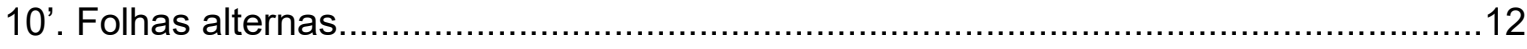

12. Folhas compostas 13

13. Caule tipo estirpe Cocos nucifera

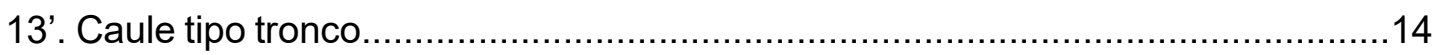

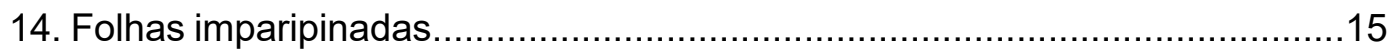

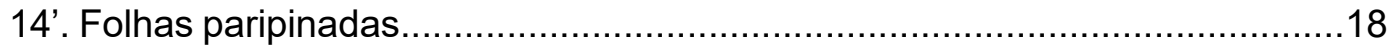

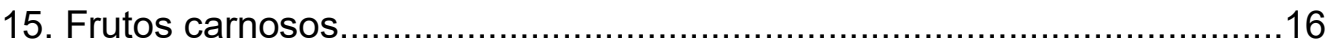

16. Base foliolar assimétrica, ápice acuminado, margem serrada; ausência de cheiro característico

Azadirachta indica

16'. Base foliolar aguda ou decurrente, ápice agudo, margem inteira; presença de nervura marginal coletora; cheiro característico

17. Copa ampla, umbeliforme, com muitos galhos; folíolos com base aguda; frutos tipo drupa com até $4 \mathrm{~cm}$ de comprimento. Spondias tuberosa

17'. Copa pouco ramificada; folíolos com base decurrente; frutos tipo drupa, maiores que $4 \mathrm{~cm}$ de comprimento Spondias sp.

15'. Frutos secos, indeiscentes, tipo sâmara. Pterogyne nitens 
18. Frutos tipo legume, deiscente; flores brancas; inflorescência racemo.

Goniorrhachis marginata

18'. Frutos tipo legume, indeiscente; flores amarelo-ouro; inflorescência cacho

Cassia fistula

12'. Folhas recompostas 19

19. Tronco armado, com acúleos.

Paubrasilia echinata

19'. Troncos inermes.

20. Folhas alternas dísticas; foliólulos numerosos, ápice agudo, base truncada; frutos tipo legume, deiscentes; ritidoma marromescamoso Cenostigma pluviosum

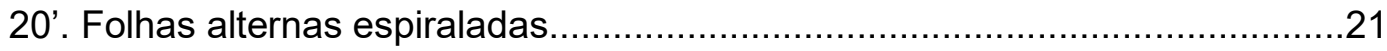

21. Frutos tipo legume

22. Inflorescência glomérulo. .23

23. Nectário no pecíolo ou ráquis; foliólulos discolores, face adaxial lustrosa

Albizia polycephala

23'. Nectários ausentes; foliólulos concolores....Leucaena leucocephala 22'. Inflorescência racemo; pétalas unguiculadas; frutos tipo legume, lenhosos. Delonix regia

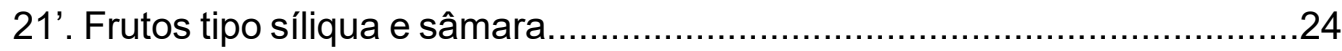

24. Frutos tipo síliqua; flores braco-creme; folhas podendo ser tripenada Moringa oleifera 24'. Frutos tipo sâmara; flores amarelo-ouro; foliólulos numerosos Peltophorum dubium

A família mais representativa em número de espécies e a segunda em número de indivíduos foi Fabaceae, apresentando 11 indivíduos distribuídos em 10 espécies, seguida de Anacardiaceae com 7 indivíduos alocados em quatro espécies, Bignoniaceae e Moraceae com 6 indivíduos pertencentes a duas espécies cada (Tabela 1; Figura 3). Moquilea tomentosa, Handroathus crysotrichus, Azadirachta indica e Ficus benjamina foram as espécies mais frequentes, com 44, 5, 4 e 4 indivíduos, respectivamente. Observou-se que $64 \%$ das espécies apresentaram apenas 1 indivíduo. 


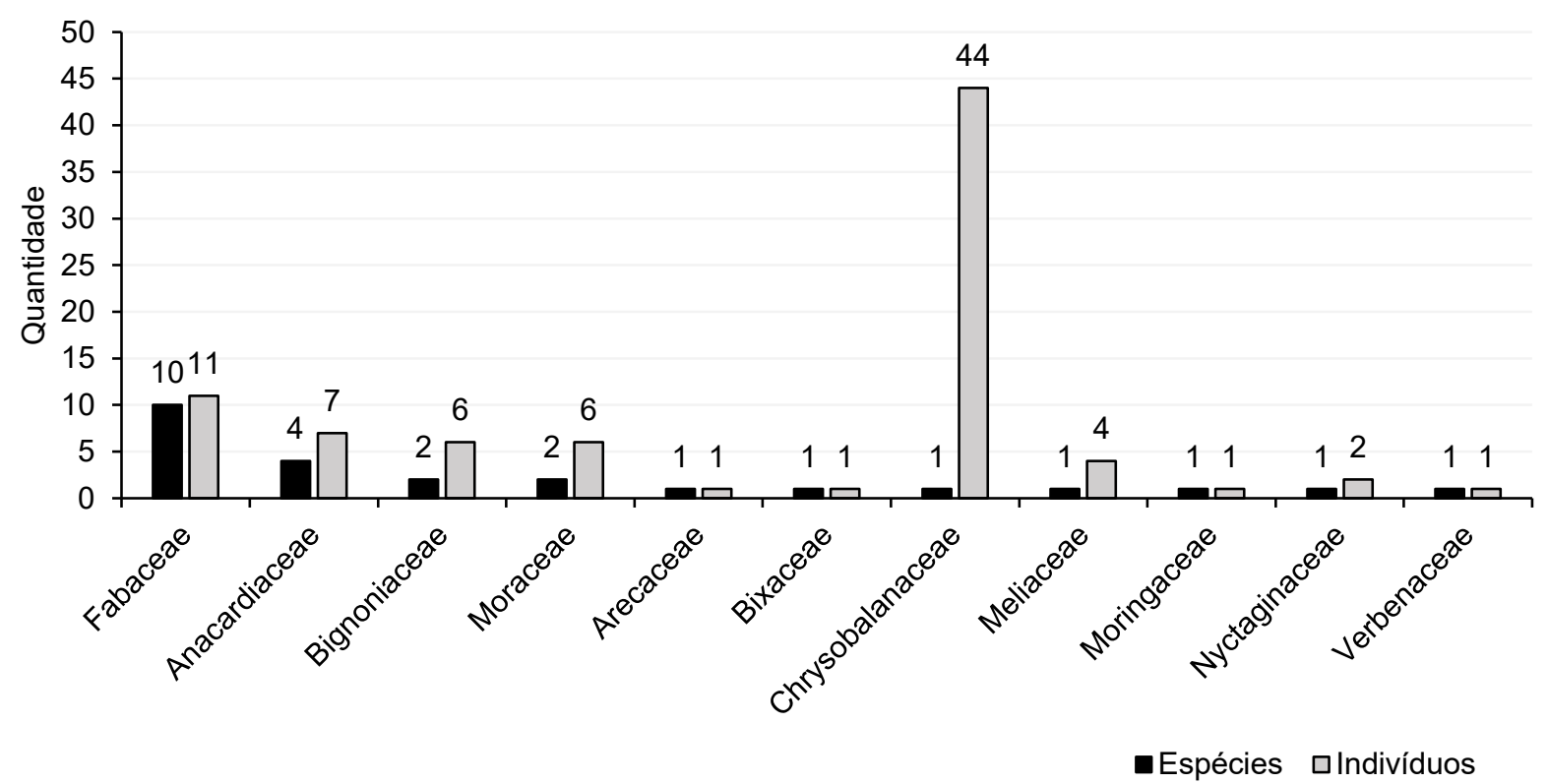

Figura 3. Frequência dos indivíduos e das espécies por família botânica, na Escola Estadual Prof. ${ }^{\text {a }}$ Clara Menezes Dias, Jaíba, MG.

Figure 3. Frequency of individuals and species by botanical family, at the Prof. ${ }^{a}$ Clara Menezes Dias State School, Jaíba, MG.

A maior diversidade de Fabaceae (Figura 2) pode ser explicada devido o grupo ser o mais empregado na arborização urbana brasileira (SOUZA; LORENZI, 2005), o que populariza o uso das espécies. Em contrapartida, a frequência de 40\% da família, encontra-se 10\% acima do recomendado por Santamour e Frank (2004), que indicam valores não superiores a 30\%. Como os agrupamentos botânicos dispõem de similaridade genética, a ação de doenças e pragas podem ser favorecidas. Com a intenção de minimizar estes fatores, além de intempéries às quais as espécies possam ser submetidas, é necessário que haja uma distribuição regular dos indivíduos, para assegurar uma menor vulnerabilidade ambiental (SANTAMOUR; FRANK, 2004).

Anacardiaceae possui grande importância econômica, sendo bastante utilizada na alimentação e na arborização urbana. A família tem como destaque diversas espécies frutíferas, caso de Mangifera indica, uma das espécies mais notórias deste inventário. Popularmente conhecida como mangueira, é um táxon exótico originário da Índia, muito empregado nas áreas verdes e em ambientes estudantis públicos e privados (LESSI; BATAGHIN; PIRES, 2017; DA SILVA; DE SOUSA, 2018). A quantidade expressiva dos seus frutos grandes e carnosos podem se tornar um problema em vias públicas, uma vez que podem cair sobre as pessoas e veículos, gerando acidentes. Por outro lado, compreendem uma alternativa para a alimentação. A espécie apresenta copa larga e por ser perene, serve de abrigo para a fauna e fornece sombra durante todo o ano, variável importante em Jaíba, devido aos elevados índices de incidência solar. Deste modo, a mangueira possui importante papel na arborização da EEPCMD, pois, além das vantagens supracitadas, situa-se em um espaço aberto, distante de calçadas (anulando o risco de rachaduras devido raízes agressivas) e fiações elétricas. 
Outra família muito utilizada na arborização urbana e paisagismo é a Bignoniaceae, devido a floração intensa de algumas espécies e madeira altamente resistente à ação de microrganismos deterioradores (FARIA; MONTEIRO; FISCH, 2007), a exemplo, Handroanthus impetiginosus (ipê-roxo) e Handroanthus chrysotrichus (ipê-amarelo), presentes na EEPCMD. A maior frequência de Chrysobalanaceae pode ser justificada pelos resultados satisfatórios de Moquilea tomentosa quanto a adaptabilidade, sombreamento, resistência e facilidade de cultivo em praticamente todas as regiões brasileiras (MIRANDA et al., 2015). Porém, sua frequência foi de $52.38 \%$, número $42.38 \%$ acima do recomendado em um bom planejamento de arborização urbana (SANTAMOUR; FRANK, 2004). O domínio de uma espécie é capaz de facilitar a propagação de pragas, podendo assim, dizimar toda a população.

Considerando a origem das espécies, $32 \%$ são exóticas cultivadas, $24 \%$ nativas do Brasil, $24 \%$ nativas da região, $12 \%$ são exóticas naturalizadas (Tabela 1). O restante de $8 \%$ não foi possível classificar devido identificação até o nível de gênero. O fato de $48 \%$ serem plantas nativas é um bom indicativo de uso das plantas brasileiras, visto que se recomenda para a arborização urbana espécies nativas, sobretudo, as da região. Assim, destaca-se a presença de espécies típicas e emblemáticas da vegetação do município de Jaíba (Floresta estacional decidual), Spondias tuberosa, Handroanthus impetiginosus, Cenostigma pluviosum e Peltophorum dubium.

Por muito tempo, espécies exóticas foram mal vistas na arborização urbana, porém, não se deve minimizar a importância deste grupo, até mesmo do ponto de vista conservacionista, e que o seu emprego é comum seja pelo fator estético, sanitário e ausência de pragas específicas (SJÖMAN et al., 2016). Os autores ainda afirmam que as espécies exóticas não compreendem um problema, mas sim as que dispõem de caráter invasor, pois se reproduzem, geram descendentes férteis e mantêm grandes populações viáveis no ambiente. As espécies Azadirachta indica e Leucaena leucocephala são caracterizadas como invasoras, devendo ser redobrado o cuidado com o comportamento de seus indivíduos na EEPCMD, bem como o manejo.

No geral, publicações técnicas e sites governamentais relacionados à silvicultura, ecologia e planejamento urbano penalizam o uso de espécies exóticas, no entanto, é pouco o conhecimento sobre o emprego desse grupo de vegetais no mundo (SJÖMAN et al., 2016). No norte de Minas Gerais não existem estudos que avaliem o comportamento destes vegetais. Ressalta-se que tais espécies devem ser utilizadas como ferramentas, dado que, a depender da situação, trazem mais benefícios ao ambiente, como é o caso da presença de Manguifera indica e Ficus benjamina na EEPCMD. Por possuírem copas frondosas e serem perenes, fornecem sombra abundante em um local com elevada incidência solar. 


\section{Síndromes de polinização e dispersão}

Em relação aos agentes polinizadores abióticos, a polinização pelo vento foi observada em $4 \%$ das espécies. Dentre as polinizações bióticas, a melitofilia ocorreu em $88 \%$ das espécies, enquanto a psicofilia ocorreu em $8 \%$ (Tabela 1, Figura 4). A melitofilia se configura como a síndrome predominante nas espécies nativas e exóticas, sendo que nas nativas da região verifica-se somente esta síndrome. O único agrupamento que houve a presença de todas as síndromes de polinização evidenciadas no trabalho foram as espécies exóticas (Figura 4).

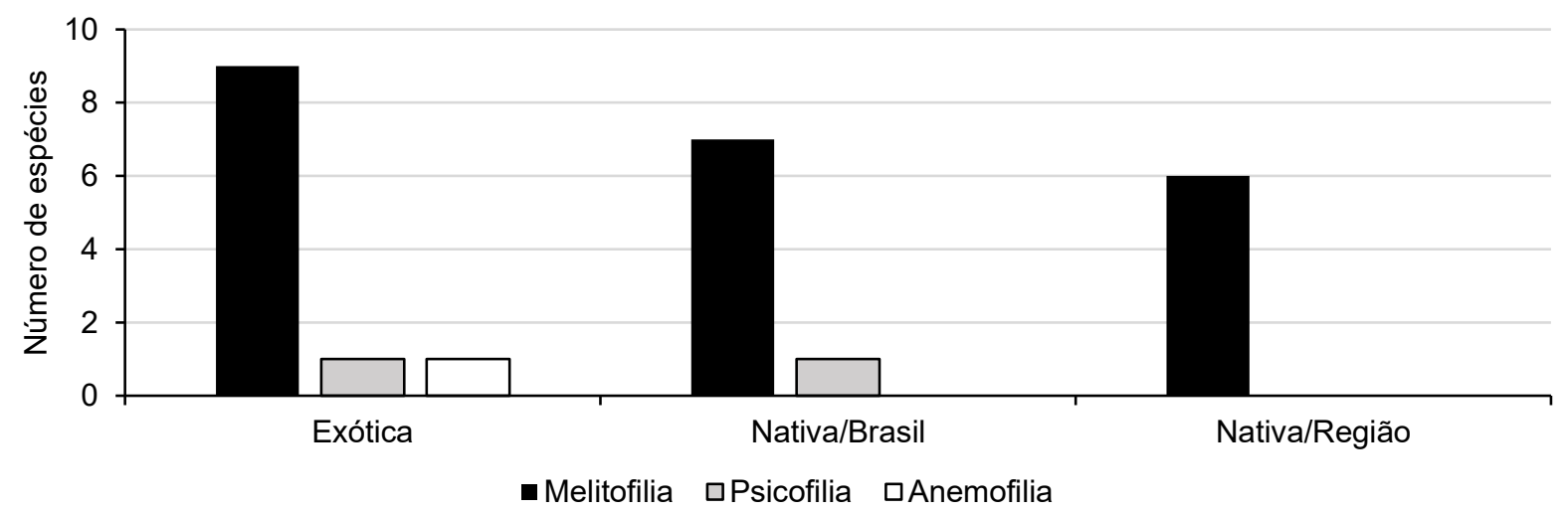

Figura 4. Síndrome de polinização em relação à origem das espécies analisadas, na Escola Estadual Prof. ${ }^{a}$ Clara Menezes Dias, Jaíba, MG.

Figure 4. Pollination syndrome in relation to the origin of the analyzed species, at Prof. ${ }^{a}$ Clara Menezes Dias State School, Jaíba, MG.

A predominância da melitofilia, reforça a importância da família Fabaceae como uma das maiores fontes de recursos alimentares (néctar e pólen) para as abelhas (FAEGRI; VAN DER PIJL, 1979). Os mesmos autores concluem que tal eficiência está diretamente relacionada às características das flores, associadas à morfofisiologia e comportamento das abelhas e vespas, o que confere maior vantagem entre os demais polinizadores. Deste modo, fica evidente a importância da arborização urbana para a manutenção deste grupo de polinizadores. 
Dentre as síndromes de dispersão primária abióticas, a anemocoria e a autocoria foram as mais representativas, ocorrendo em $20 \%$ das espécies cada uma, e em $14,28 \%$ e $7,14 \%$ dos indivíduos, respectivamente; seguida da barocoria (16\% das espécies - 3,57\% dos indivíduos) e hidrocoria (4\% das espécies - 1,19\% dos indivíduos) (Figura 5). A maior representatividade anemocórica se deve a presença das bignoniáceas, pois possuem majoritariamente frutos secos. O elevado percentual autocórico é devido o predomínio de fabáceas.

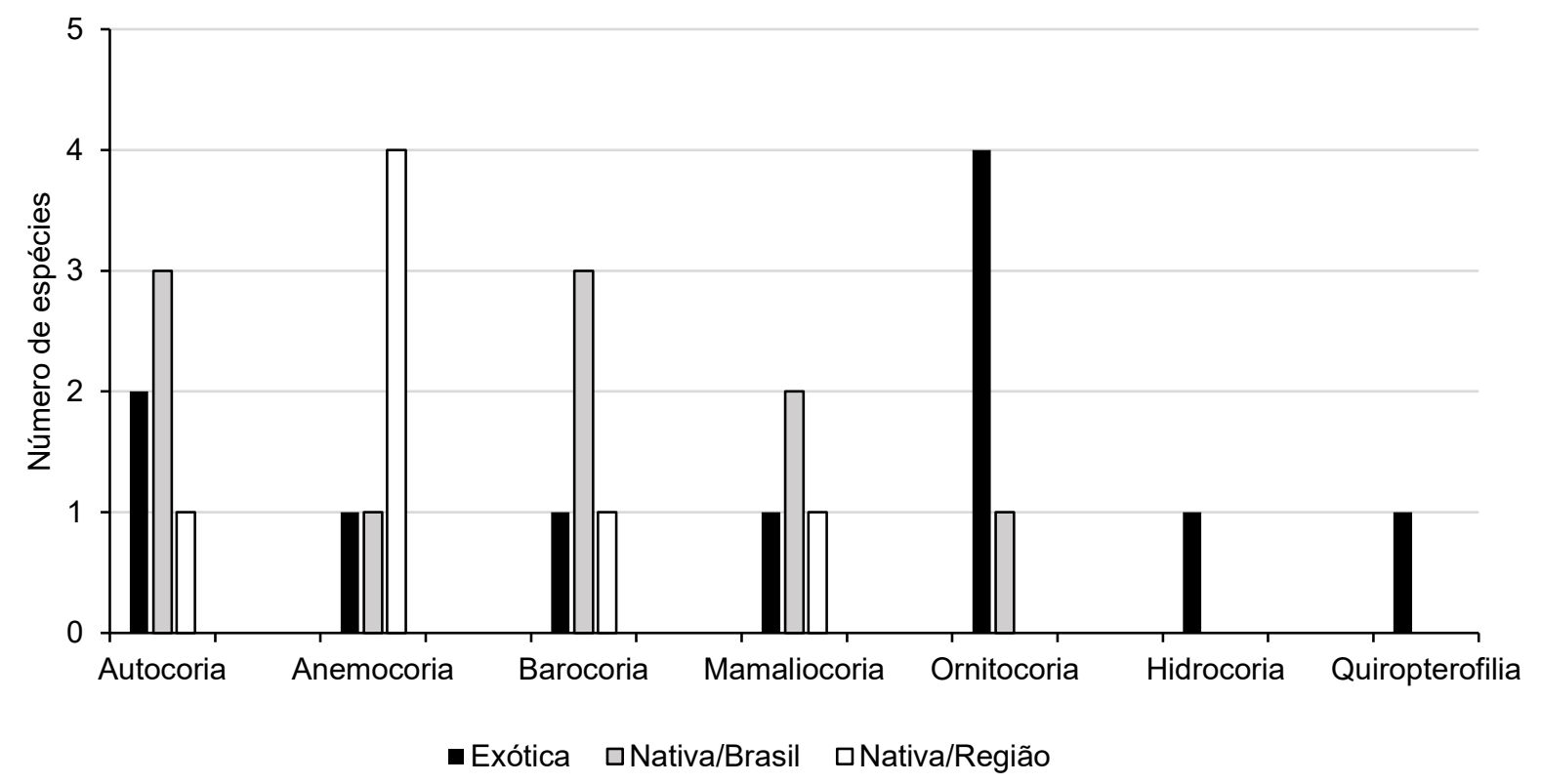

Figura 5. Síndrome de dispersão primária em relação à origem das espécies analisadas, na Escola Estadual Prof. a Clara Menezes Dias, Jaíba, MG.

Figure 5. Primary dispersion syndrome in relation to the origin of the species analyzed, at Prof. ${ }^{a}$ Clara Menezes Dias State School, Jaíba, MG.

Nas síndromes de dispersão primária bióticas, a ornitocoria ocorreu em $20 \%$ das espécies (14,28\% dos indivíduos); seguida da mamaliocoria em $16 \%$ das espécies $(60,71 \%$ dos indivíduos) e quiropterocoria em $4 \%$ das espécies (4,76\% dos indivíduos). Dentre estas espécies, $56 \%$ são endozoocóricas (quando ocorre a ingestão de sementes, frutos ou parte deles), 11\% são sinzoocóricas (quando os diásporos são intencionalmente enterrados, acumulados ou carregados intencionalmente) e em $36 \%$ há a combinação destes dois processos (Tabela1, Figura 5). A dispersão de frutos das espécies levantadas não é uma característica estudada na maioria dos trabalhos sobre arborização urbana. Todavia é de extrema importância, pois aponta quais os tipos de animais que podem estar sendo atraídos para as áreas urbanas e possivelmente dispersando as sementes ou frutos. A representatividade deste agrupamento de síndromes se deve ao grande número de espécies que apresentam frutos com características que os tornam atrativos, tais como odor, sabor e cor (FENNER, 1985). Espécies frutíferas são elementos importantes na arborização, uma vez que atraem a fauna silvestre e alimentam pássaros e morcegos, animais abundantes em cidades (BIAGOLINI; LOURENÇO, 2018). 
Considerando síndromes de dispersão primária, bióticas e abióticas, $16 \%$ das espécies apresentaram a combinação de duas síndromes de dispersão (Tabela 1), como o que ocorre em Spondias sp., Spondias tuberosa e Moquilea tomentosa. A autocoria e a ornitocoria foram as mais frequentes nas espécies exóticas, enquanto a autocoria e barocoria foram mais frequentes nas nativas do Brasil, a anemocoria predominou nas nativas da região (Tabela 1, Figura 4). 0 fato de o maior número de espécies dispersas pelo vento estarem entre as nativas da região se deve a ecofisiologia típica dos frutos (secos) que são adaptados à condição climática regional.

\section{Estrutura e índices de diversidade}

Em relação ao CAP, 59,52\% ( $N=50)$ dos indivíduos são senis, $13,09 \%(\mathrm{~N}=11)$ são adultos e 27,38\% ( $N=23)$ são jovens. As maiores circunferências estão entre $90 \mathrm{~cm}$ e $135 \mathrm{~cm}$, e compreendem as espécies Moquilea tomentosa e Ficus bejamina, o que também as incluiu, juntamente com Mangifera indica como as mais dominantes e com as maiores densidades absolutas (Tabela 1). Estes dados demostram que a comunidade é majoritariamente senil, sendo dos primeiros plantios de árvores na EEPCMD. Analisando registros fotográficos disponibilizados pela escola, os exemplares de Moquilea tomentosa e Ficus bejamina (que juntos totalizam 57\% da comunidade arbórea) possuem aproximadamente 20 anos, confirmando a inferência supracitada.

Considerando a altura, 95,24\% estão com, no máximo, 9 metros (pequeno porte) e 4,76\% estão entre 9 e 20 metros (médio a grande porte) (PAIVA; GONÇALVES, 2004). Entre as espécies de médio e grande porte, estão Moquilea tomentosa, Ficus bejamina, Cenostigma pluviosum, plantas que possuem copas frondosas e que assim, possuem papel importante na produção de sombra e decréscimo da temperatura, visto que Jaíba apresenta forte incidência solar durante 8 meses (INMET, 2020). Apesar de apresentar apenas um indivíduo, Cenostigma pluviosum tem a capacidade de diminuir a temperatura entre 12 e $16{ }^{\circ} \mathrm{C}$ em conjunto de árvores e individualmente entre 12,5 e $14,5^{\circ} \mathrm{C}$ (DE ABREU-HARBICH; LABAKI; MATZARAKIS, 2015), podendo ser considerada uma espécie chave no ambiente, devido promover melhor conforto térmico.

O índice de Shannon foi de 2,11 (Tabela 2). Essa métrica é muito utilizada para medir a diversidade florística em áreas urbanas, pois leva em consideração o número de espécies e a sua equabilidade (ROMANI et al., 2012). Considerando que a variação deste índice é de aproximadamente $1,5-3,5$, o resultado encontrado pode ser colocado como intermediário para o total de indivíduos amostrados, quando comparado a outros estudos (Tabela 2). 
Tabela 2. Índice de Shannon ( $\left.\mathrm{H}^{\prime}\right)$ e equabilidade (J') deste trabalho e de outros.

Table 2. Shannon's index $\left(\mathrm{H}^{\prime}\right)$ and equability $(\mathrm{J} /)$ of this study and others.

\begin{tabular}{ccccc} 
Autor & Local & $\begin{array}{c}\text { Número de } \\
\text { individuos }\end{array}$ & H' & J' \\
\hline DOS AUTORES, 2020 & Jaíba, MG & 84 & 2,11 & 0,657 \\
\hline \multirow{2}{*}{ RODRIGUES; COPATTI, 2009 } & \multirow{2}{*}{ São Vicente do Sul, RS } & $\begin{array}{c}54 \\
21\end{array}$ & $\begin{array}{c}1,19 \\
0,693\end{array}$ & 0,917 \\
& & 16 & 0,828 & 0,893 \\
\hline \multirow{2}{*}{ LESSI; BATAGHIN; PIRES, 2017 } & São Carlos, SP & 3020 & \multirow{2}{*}{3,89} & 0,799 \\
\hline
\end{tabular}

O índice de Equabilidade foi 0,657 (Tabela 2). Este compreende uma derivação do índice de diversidade de Shannon e possibilita representar a uniformidade da distribuição dos indivíduos entre as espécies existentes, sendo que seu valor apresenta uma variação de 0 (uniformidade mínima) a 1 (uniformidade máxima). Desse modo, o resultado indica baixa diversidade e, consequentemente, desuniformidade na distribuição dos indivíduos na área quando comparado ao levantamento conduzido em três escolas de São Vicente do Sul-RS.

\section{CONCLUSÕES}

A dendroflora da Escola Estadual Professora Clara Menezes Dias apresenta predomínio de espécies nativas (57\%). Leucaena leucocephala e Azadirachta indica são plantas exóticas invasoras, sendo aconselhável a substituição gradativa.

A síndrome de polinização predominante foi a melitofilia e dispersão foi a anemocoria. O índice de Shannon $(2,11)$ demonstrou que o ambiente apresenta uma quantidade expressiva de espécies, porém, com base nas proporções do número de indivíduos em relação ao número de espécies na escola, a Equabilidade de 0,657 indica um padrão de distribuição não uniforme.

Pelo fato de ser verificado expressiva frequência da espécie Moquilea tomentosa (52,38\%), sugere-se a adoção de medidas para introdução de novas espécies ou aumento do número de indivíduos de espécies já existentes no ambiente, de modo a evitar a perda do patrimônio arbóreo em caso de um surto de praga ou doença. Espécies como Mangifera indica, Spondias tuberosa, Bauhinia variegata var. candida, Cenostigma pluviosum, Paubrasilia echinata e Peltophorum dubium possuem, no geral, características importantes para inserção em ambiente escolar, de modo especial, nesta mesorregião. Estas apresentam copas frondosas que propiciam e fornecimento de sombra, redução da temperatura e melhoria do conforto térmico, além do valor ornamental.

A chave de identificação fornecerá subsídios para identificação das espécies presentes na arborização escolar. Além disso, poderá ser usada nas aulas de Biologia e Geografia. 


\section{AGRADECIMENTOS}

Agradecemos a diretora da Escola Estadual Prof. ${ }^{a}$. Clara Menezes Dias, Eliana Alves Camargo Melo pelo apoio e incentivo na realização deste trabalho.

\section{REFERÊNCIAS}

ALMAS, A. D.; CONWAY, T. M. Residential knowledge of native tree species: A case study of residents in four southern Ontario municipalities. Environmental management, Saskatoon, v. 59, n. 1, p. 21-33, 2016.

BIAGOLINI, C. H.; LOURENÇO, R. W. Relação entre avifauna e plantas frutíferas em 10 parques lineares da cidade de São Paulo, (Brasil). Conhecimento Interativo, Curitiba, v. 12, n. 2, p. 7081, 2018.

CABRAL, P. I. D. Arborização urbana: problemas e benefícios. Revista Especialize On-line IPOG, Goiânia, n. 06, p. 1-15, 2013.

DA SILVA, S. T.; DE SOUSA, B. H. Diagnóstico da arborização urbana do município de Guarabira-Paraíba. Paisagem E Ambiente, São Paulo, n. 41, p. 167-184, 2018.

DE ABREU-HARBICH, L, V.; LABAKI, L. C.; MATZARAKIS, A. Effect of tree planting design and tree species on human thermal comfort in the tropics. Landscape and Urban Planning, Michigan, v. 138, p. 99-109, 2015.

DE SOUZA, C. P.; NOGUEIRA, W. G. C.; DA COSTA SARAIVA, A. L. B. Conforto térmico humano em ambientes escolares de clima semiárido. Revista Geolnterações, Assú, v. 2, n. 1, p. 95-113, 2018.

DOS SANTOS MAMEDE, J. S.; SOUZA F. F.; SANTOS A. F. A.; DUTRA R. M. C.; NETO R. M. R. Levantamento quali-quantitativo de espécies arbóreas e arbustivas na arborização urbana do município de Paranaíta, Mato Grosso. Biodiversidade, Cuiabá, v. 13, n. 2, 2014.

FAEGRI, K.; VAN DER PIJL, L. The principles of pollination ecology. New York: Pergamon Press, v. 64, p. 6-7, 1979.

FARIA, J. L. G.; MONTEIRO, E. A.; FISCH, S. T. V. Arborização de vias públicas do município de Jacareí-SP. Revista da sociedade brasileira de arborização urbana, Piracicaba, v. 2, n. 4, p. 20-33, 2007.

FENNER, M. Seed ecology. London: Chapman and Hall, 1985.

FIRMO, D. H. T.; FREITAS, D. A.; DURÃES, A. F. S.; SILVA, A. C.; ALMEIDA, E. F. A. Arborização urbana: uma imprescindível prática de manejo dos espaços urbanos/Urban afforestation: an indispensable practice of urban space management. Brazilian Journal of Animal and Environmental Research, São José dos Pinhais, v. 2, n. 5, p. 1584-1601, 2019.

Flora do Brasil 2020 em construção. Jardim Botânico do Rio de Janeiro. Disponível em: <http://floradobrasil.jbri.gov.br/ >. Acesso em: 19 abr. 2021.

GONÇALVES, E.G.; LORENZI, H. Morfologia Vegetal: organografia e dicionário ilustrado de Morfologia das plantas vasculares. Ed. Plantarum, São Paulo. 416p, 2007. 
IBGE (Instituto Brasileiro de Geografia e Estatística). Brasil. Disponível em: < https://cidades.ibge.gov.br/ >. Acesso em: 27 mai 2020.

INMET (Instituto Nacional de Meteorologia). Dados meteorológicos. Disponível em: < https://bdmep.inmet.gov.br/ >. Acesso em: 25 jun 2020.

LESSI, B. F.; BATAGHIN, F. A.; PIRES, J. S. R. Diversity and distribution of trees on the Federal University of São Carlos campus, Brazil: implications for conservation and management. Revista da Sociedade Brasileira de Arborização Urbana, Piracicaba, v. 12, n. 1, p. 92-104, 2017.

MIRANDA, Y. C.; MACHADO, M.; SILVA, L. S.; ESTEVAM, R.; NETO, F. F. M.; CAXAMBU, M. G. Análise quali-quantitativa da arborização de ruas do município de Godoy Moreira-PR. Revista da Sociedade Brasileira de Arborização Urbana, Piracicaba, v. 10, n. 1, p. 71-81, 2015.

PAIVA, H. N.; GONÇALVES, W. Árvores para o ambiente urbano. Viçosa, MG: Aprenda Fácil Editora, 2004.

RODRIGUES, L. S.; COPATTI, C. E. Conforto ambiental e Diversidade arbórea das escolas da área urbana de São Vicente do Sul/RS. Biodiversidade Pampeana, Uruguaiana, v. 7, n. 1, 2009.

ROMANI, G. N.; GIMENES, R.; SILVA, M. T.; PIVETTA, K. F. L.; BATISTA, G. S. Análise qualiquantitativa da arborização na praça XV de novembro em Ribeirão Preto-SP, Brasil. Revista Árvore, Viçosa, v. 36, n. 3, p. 479-487, 2012.

SANTAMOUR, J. R; FRANK, S. Trees for urban planting: diversity uniformity, and common sense. C. Elevitch, The Overstory Book: Cultivating connections with trees, p. 396-399, 2004.

SJÖMAN, H.; MORGENROTH, J.; SJOMAN, D. J.; SAEBO, A.; KOWARIK, I. Diversification of the urban forest-Can we afford to exclude exotic tree species? Urban Forestry \& Urban Greening, Amsterdã, v. 18, p. 237-241, 2016.

SOUSA, I. S. C.; MAIA, L. H. F.; SOARES, M. A. V. S.; RODRIGUES. R. S.; PIRES, G. R.; SILVA, L. P.; DALTO, P. H. A arborização escolar como ferramenta de ensino para a promoção da educação ambiental. Anais do Integra, Teresina, v. 2, 2019.

SOUZA, V. C.; LORENZI, H. Botânica sistemática: guia ilustrado para identificação das famílias de Angiospermas da flora brasileira, baseado em APG II. Instituto Plantarum, 2005.

VAN DER PIJL, L. Principles of dispersal in higher plants. Berlim: Springer - Verlag, 1982. $215 p$. 